\title{
A Novel High Power LED Module Design on Aluminum Board (COAB) by Packaging Multi-Die in both Series and Parallel
}

\author{
Jiumming Lin ${ }^{1, a}$ and Chenghung $\operatorname{Lin}^{2, b}$ \\ ${ }^{1}$ Department of Electronic Engineering, Chung-Hua University, Taiwan \\ ${ }^{2} \mathrm{Ph}$. D. Program in Engineering Science, Chung-Hua University, Taiwan \\ ajmlin@chu.edu.tw, bb09306014@chu.edu.tw
}

Keywords: LED; Junction temperature; Heat dissipation; Chip on aluminum board (COAB)

\begin{abstract}
To decrease the LED operating temperature this paper presents a novel high power LED COAB (Chip on Aluminum Board) bonding method, the heat dissipation performance was studied by packaging the multi-die in the combination of series and parallel. The trade-off parameters were the bonding distance and driving voltage. The dies were connected in a combination of 3 dies in series and 3 sets in parallel ( $3 \times 3$ square matrix pattern). If the separation distance of die bonding was $1.5 \mathrm{~mm}$, the temperatures on the top surface of center LED with driving voltage of 8 (9) Volts was $75.2(90.5){ }^{\circ} \mathrm{C}$. On the other hand, if the separation distance reduced to $1.0 \mathrm{~mm}$ with the driving voltage of 8 (9) Volts, then the temperatures at the top surface of center LED would be increased to $75.7(115.2){ }^{\circ} \mathrm{C}$. Thus for the LEDs efficiency kept at $80 \%$ of those at $25^{\circ} \mathrm{C}$, the final choice of die bonding distance and driving voltage were $1.0 \mathrm{~mm}$ and $8 \mathrm{~V}$, respectively.
\end{abstract}

\section{Introduction}

The LED has several advantages, such as low power dissipation and long term reliability. Thus it can replace the traditional light bulb for illumination [1-2]. But as the applying power to the LED is increased, the heat dissipation problem would reduce the efficiency dramatically [3-4]. The LED is useless when the efficiency is reduced to 70\% [5-6]. The efficiency will be decreased as the working temperature increased and times go by. The LED is extensively applied in the area of illumination right now, especially in the fields of high power RGB white LED illumination. So the thermal dissipation problem should be solved. The factors that affect the efficiency of thermal dissipation problem are as LED chip, carrier substrate, die packaging material and method.

This paper presents a novel high power LED COAB (Chip on Aluminum Board) bonding method, because not only the heat dissipation path of bonding the chip on board but the thermal resistance of aluminum substrate can be reduced to increase the efficiency. Besides, COAB technology could simplify the circuit design and also reduce the cost. The heat dissipation performance was studied by packaging the multi-die in the combination of series and parallel. The trade-off parameters were the bonding distance and driving voltage. The dies were connected in a combination of 3 dies in series and 3 sets in parallel ( $3 \times 3$ square matrix pattern). If the separation distance was $1.5 \mathrm{~mm}$, the temperatures on the top surface of center LED with driving voltage of 8 (9) Volts was $75.2(90.5){ }^{\circ} \mathrm{C}$. On the other hand, if the separation distance reduced to $1.0 \mathrm{~mm}$ with the driving voltage of 8 (9) Volts, then the temperatures at the top surface of center LED would be increased to 75.7 (115.2) ${ }^{\circ} \mathrm{C}$. Thus for the LEDs efficiency kept at $80 \%$ of those at $25^{\circ} \mathrm{C}$, the final choice of die bonding distance and driving voltage were $1.0 \mathrm{~mm}$ and $8 \mathrm{~V}$, respectively. The other contains of this paper are as follows: the second section is for the thermal dissipation problem. Section 3 briefs the experiments and procedures. The final section is conclusion. 


\section{Thermal Dissipation Problem}

The In general, the working temperature of LED p-n junction is $25^{\circ} \mathrm{C}$, and the efficiency is normalized as $100 \%$. When the working temperature is increased to $75^{\circ} \mathrm{C}$, then the efficiency would be decreased to $80 \%$, and even lowering to $40 \%$ as the temperature is $175^{\circ} \mathrm{C}$. Thus the LED efficiency and life-cycle are inversely proportional to the working temperature.

In general, if the efficiency to dissipate the heat generated by the LED is lower, then its p-n junction temperature would be increased, and so does the LED efficiency be decreased in the next moment, and finally the LED reliability, lighting efficiency and performance would be faded quickly. Fig. 1 shows the relationship of LED efficiency and its junction temperature, if the junction temperature is increased from $25^{\circ} \mathrm{C}$ to $100^{\circ} \mathrm{C}$, then the efficiency of each kind of LED would be reduced from $20 \%$ (white) to $75 \%$ (yellow LED). Besides, Fig. 2 shows that the LED life-cycle is also inversely proportional to its working temperature, and when the working temperature is increased from $63^{\circ} \mathrm{C}$ to $74^{\circ} \mathrm{C}$, the average life-cycle (for lighting efficiency: $70 \%$ ) would be reduced by $25 \%$.

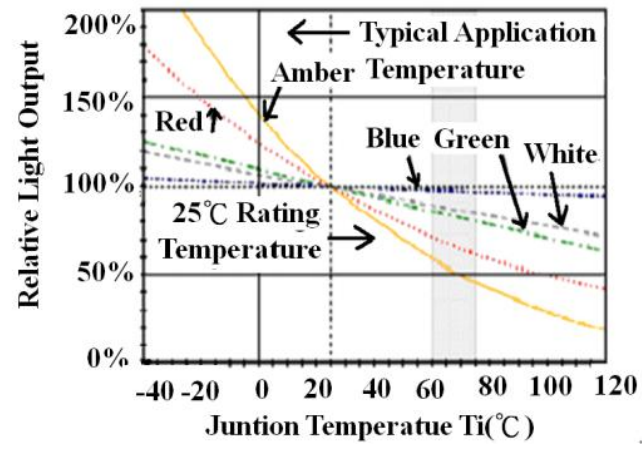

Figure 1. Relationship of LED efficiency and junction temperature

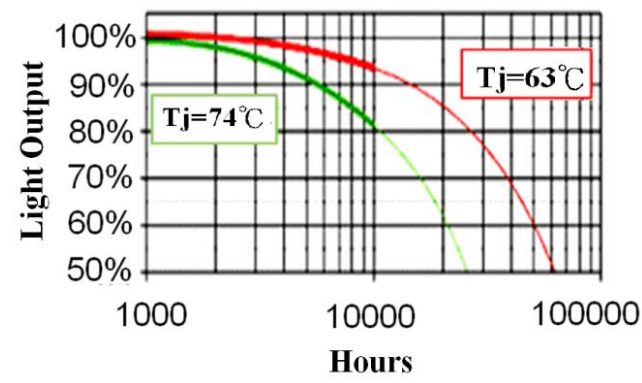

Figure 2. Relationships of LED life-cycle, light efficiency and working temperature

In this paper the $\mathrm{COAB}$ (Chip On Aluminum Board) package technology was applied to package LED chip, because not only the heat dissipation path of bonding the chip on board but the thermal resistance of aluminum substrate can be reduced to increase the efficiency. Besides, COAB technology could simplify the circuit design and also reduce the cost.

\section{Experiments and Procedures}

An aluminum substrate $(33 \mathrm{~mm} \times 33 \mathrm{~mm} \times 1.5 \mathrm{~mm})$ with better heat dissipation performance was applied as the substrate. The chip (45mils $\times 45$ mils) was blue LED (450-452 nm) with epi-layer technology. The LED dies were arranged in a $3 \times 3$ matrix pattern with 9 LEDs connected in 3 series and 3 parallel. The major topic of this research is to find the better combination of separation range for die bonding and its driving voltage. Three kinds of bonding distance (BD) as shown in Fig. 3 were performed for comparison, such as $0.5,1.0 \mathrm{~mm}$, and $1.5 \mathrm{~mm}$. On the other hand, two driving voltages, 8 or 9 Volts, were applied to the LEDs for working point selection. The thermal couple was applied to take temperature measurements at the top and bottom surfaces of the center die and substrate, respectively. 


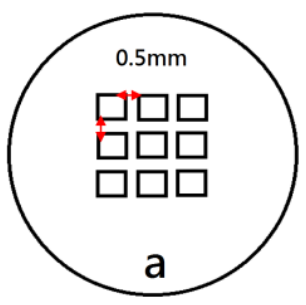

(a) $0.5 \mathrm{~mm}$

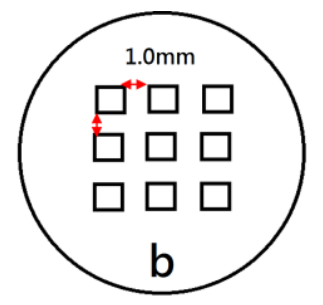

(b) $1.0 \mathrm{~mm}$

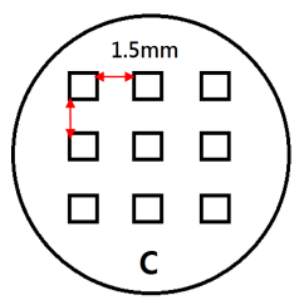

(c) $1.5 \mathrm{~mm}$

Figure 3. Three kinds of bonding distance for comparison. (a) $0.5 \mathrm{~mm}$, (b) $1.0 \mathrm{~mm}$ and (c) $1.5 \mathrm{~mm}$

Step 1: Chip Bonding. Making three kinds of LED die bonding method as shown in Fig. 3, the separation distance of the die were $0.5,1.0 \mathrm{~mm}$, and $1.5 \mathrm{~mm}$, respectively. Then bonding LED dies on the substrate with silver paste, and curing at $150^{\circ} \mathrm{C}$ for 30 minutes with hot wind drying in an oven.

Step 2: Wire bonding. Bonding the LED dies with gold wire to the outer lead terminals (substrate kept with temperature $130^{\circ} \mathrm{C}-150^{\circ} \mathrm{C}$ ) as shown in Fig. 4 for inter-connection.

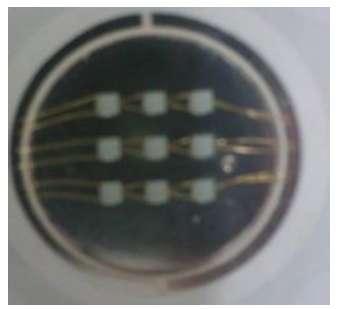

Figure 4. Bonding the chip with gold wire to outer lead terminals for inter-connection

Step 3: Temperature Measurements. Putting the LED dies in a $3 \times 3$ matrix pattern with 9 LEDs connected in 3 series and 3 parallel. Set the driving voltage as 8 or 9 Volts for two minutes in order to compare the thermal dissipation performances in equilibrium conditions. Take temperature measurements respectively at the top and bottom surfaces of the center die and substrate.

Step 4: Select the better combination of die bonding distance (BD) and driving voltage (DV). The combinations were listed in Table 1, and the corresponding measurement results were shown in Figs. 5-6. One could see all the temperatures would be approaching constant values at the testing periods of two minutes, and the temperatures applying $9 \mathrm{~V}$ were larger than those using $8 \mathrm{~V}$ for the same case.

Table 1 Combinations of separation distance for die bonding and driving voltage.

\begin{tabular}{|c|c|c|c|}
\hline Combinations & Bonding Distance (BD) & Driving Voltage (DV) & Test Point \\
\hline 1 (Fig. 5(a)) & $0.5 \mathrm{~mm}$ & $9 \mathrm{~V}$ & Top surface of center die \\
\hline 2 (Fig. 5(b)) & $1.0 \mathrm{~mm}$ & $9 \mathrm{~V}$ & Top surface of center die \\
\hline 3 (Fig. 5(c)) & $1.5 \mathrm{~mm}$ & $9 \mathrm{~V}$ & Top surface of center die \\
\hline 4 (Fig. 6(a)) & $0.5 \mathrm{~mm}$ & $9 \mathrm{~V}$ & Bottom of substrate \\
\hline 5 (Fig. 6(b)) & $1.0 \mathrm{~mm}$ & $9 \mathrm{~V}$ & Bottom of substrate \\
\hline 6 (Fig. 6(c)) & $1.5 \mathrm{~mm}$ & $9 \mathrm{~V}$ & Bottom of substrate \\
\hline
\end{tabular}

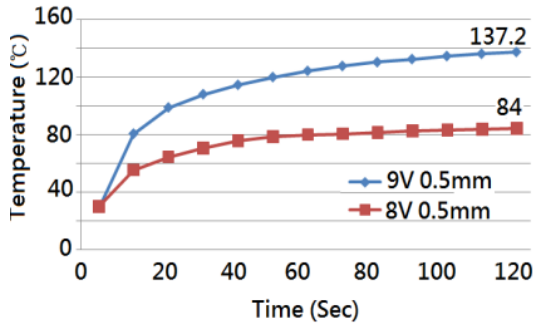

(a) $\mathrm{BD}=0.5 \mathrm{~mm}$

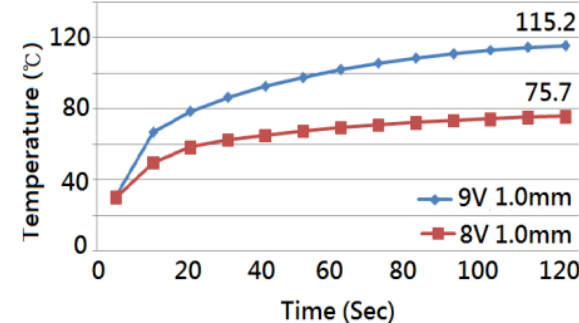

(b) $\mathrm{BD}=1.0 \mathrm{~mm}$

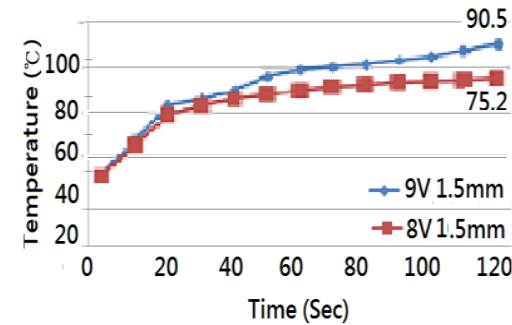

(c) $\mathrm{BD}=1.5 \mathrm{~mm}$

Figure 5. Temperature curves on center die surface by applying 8 and 9 Volts. (a) BD=0.5mm, (b) $\mathrm{BD}=1.0 \mathrm{~mm}$, and (c) $\mathrm{BD}=1.5 \mathrm{~mm}$. 

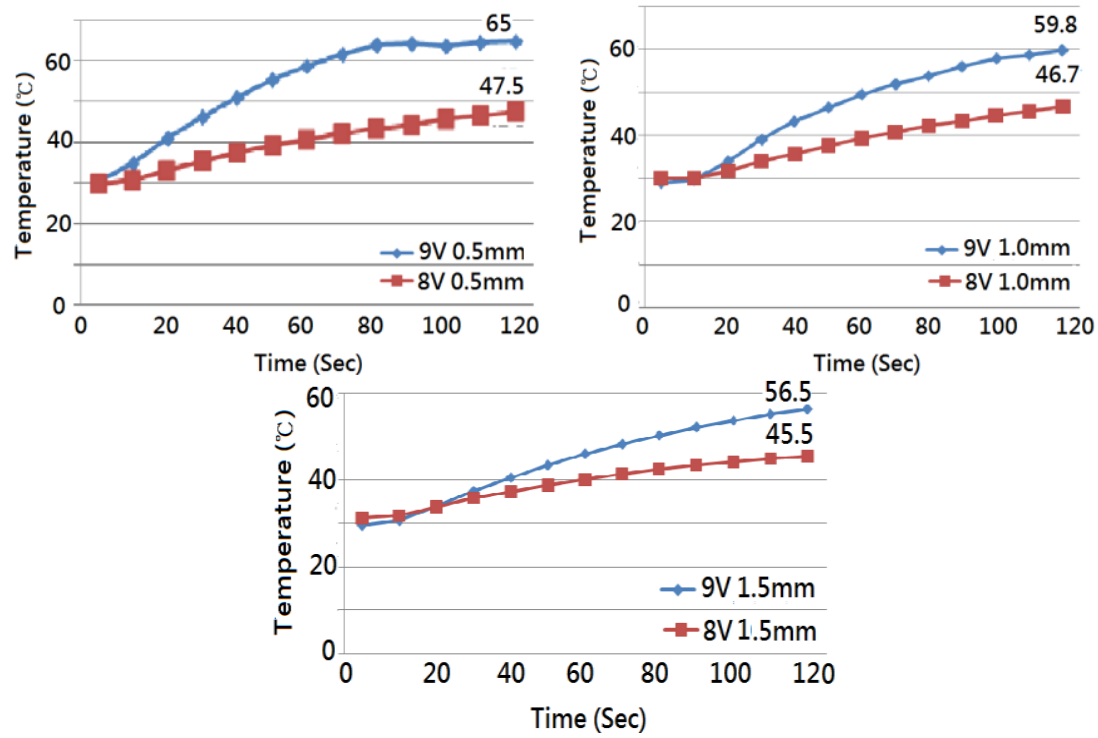
(a) $\mathrm{BD}=0.5 \mathrm{~mm}$
(b) $\mathrm{BD}=1.0 \mathrm{~mm}$
(c) $\mathrm{BD}=1.5 \mathrm{~mm}$

Figure 6. Temperature curves on bottom surface of substrate by applying 8 and 9 Volts. (a) $\mathrm{BD}=0.5 \mathrm{~mm}$, (b) $\mathrm{BD}=1.0 \mathrm{~mm}$, and (c) $\mathrm{BD}=1.5 \mathrm{~mm}$.

\section{Performance Analyses}

One could redraw the temperatures (at two minutes) on the top surface of center die versus bonding distances as shown in Fig. 7(a) for easy of comparison. The largest temperature for $\mathrm{BD}=0.5 \mathrm{~mm}$ with $9 \mathrm{~V}(8 \mathrm{~V})$ is $137.2^{\circ} \mathrm{C}\left(84^{\circ} \mathrm{C}\right)$. The largest temperature for $\mathrm{BD}=1.0 \mathrm{~mm}$ with $9 \mathrm{~V}(8 \mathrm{~V})$ is $115.2^{\circ} \mathrm{C}\left(75.7^{\circ} \mathrm{C}\right)$. Finally, the largest temperature for $\mathrm{BD}=1.5 \mathrm{~mm}$ with $9 \mathrm{~V}(8 \mathrm{~V})$ is $90.5^{\circ} \mathrm{C}\left(75.2^{\circ} \mathrm{C}\right)$. Thus, one had the following conclusion. The larger the separation ranges, the lower the temperature, and if applying $9 \mathrm{~V}$ the temperature with $\mathrm{BD}=1.5 \mathrm{~mm}$ was decreased by $46.7^{\circ} \mathrm{C}$ for the case with $0.5 \mathrm{~mm}$. Thus the separation distance of die bonding is the key parameter for design. Similarly, one could redraw the temperatures on the bottom surface of substrate (at two minutes) versus bonding distances as shown in Fig. 7b). The largest temperature for $\mathrm{BD}=0.5 \mathrm{~mm}$ with $9 \mathrm{~V}(8 \mathrm{~V})$ is $65^{\circ} \mathrm{C}\left(47.5^{\circ} \mathrm{C}\right)$. The largest temperature for $1.0 \mathrm{~mm}$ separation with $9 \mathrm{~V}(8 \mathrm{~V})$ is $59.8^{\circ} \mathrm{C}\left(46.7^{\circ} \mathrm{C}\right)$. Finally, the largest temperature for $1.5 \mathrm{~mm}$ separation with $9 \mathrm{~V}(8 \mathrm{~V})$ is $56.5^{\circ} \mathrm{C}\left(45.5^{\circ} \mathrm{C}\right)$. Thus, one had the following conclusion. The larger the bonding distances, the lower the temperature, and if applying $9 \mathrm{~V}$ the temperature with $\mathrm{BD}=1.5 \mathrm{~mm}$ was decreased by $46.7^{\circ} \mathrm{C}$ for the case with $\mathrm{BD}=0.5 \mathrm{~mm}$. Thus the bonding distance of die is the key parameter for design.
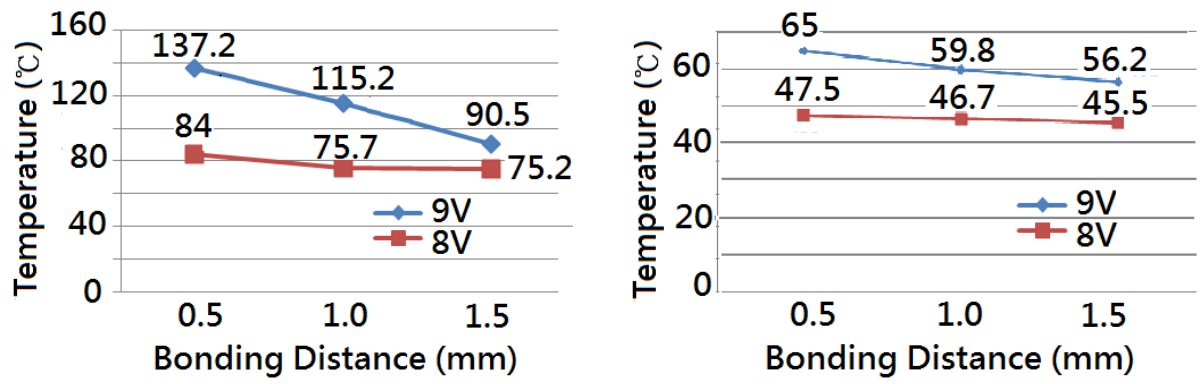

Figure 7. Temperatures vs. BD with 9V and 8V. (a) Top surface of die. (b) Bottom surface of substrate.

\section{Summary}

This paper presents a novel high power LED COAB (Chip On Aluminum Board) bonding and heat dissipation performance study, the 9 multi-die were packaged in the combination of 3 dies in series and 
3 in parallel. The die bonding distance and driving voltage are the key parameters to tradeoff. The temperatures on the top surface of LED and the bottom surface of substrate by applying 8 and 9 Volts are studied. If the bonding distance and driving voltage are respectively $1.5 \mathrm{~mm}$ and 8 (or 9) Volts; and then the temperatures on the top surface of LED and substrate of the die can be respectively as 75.2 $(90.5)^{\circ} \mathrm{C}$ and $45.5(56.5)^{\circ} \mathrm{C}$. On the other hand, if the die bonding distance reduced to $1.0 \mathrm{~mm}$ with the driving voltage of 8 (9) Volts, then the temperatures at the top and bottom of the LED surface would be increased to $75.7(115.6){ }^{\circ} \mathrm{C}$ and $46.7(59.8)^{\circ} \mathrm{C}$, respectively. Thus for the LEDs efficiency kept at $80 \%$ of those at $25^{\circ} \mathrm{C}$, the final choice of die bonding distance and driving voltage were $1.0 \mathrm{~mm}$ and $8 \mathrm{~V}$, respectively.

\section{Acknowledgements}

National Science Council supported this research with the grants: MOST 104-2221-E-216-021.

\section{References}

[1] E.Juntunen, O. Tapaninen, A. Sitomaniemi, and V. Heikkinen, Effect of phosphor encapsulant on the thermal resistance of a high-power COB LED module, IEEE Transactions on Components, Packaging and Manufacturing Technology 4. 3, 7 (2013) 1148-115.

[2] M. Cai, D.G. Yang, S. Koh, C.A. Yuan, W.B. Chen, B.Y. Wu, and G.Q. Zhang, Accelerated testing method of LED luminaries, 13th International Conference on Thermal, Mechanical and Multi-Physics Simulation and Experiments in Microelectronics and Microsystems (EuroSimE). (2012) $1 / 6-6 / 6$.

[3] A. Fan, R. Bonner, S. Sharratt, and Y.S. Ju, An innovative passive cooling method for high performance light-emitting diodes, 28th Annual IEEE Semiconductor Thermal Measurement and Management Symposium (SEMI-THERM). (2012) 319-324.

[4] S. Y. Lee, and M. Devarajan, Thermal analysis of multi-chip LED package with different position and ambient temperatures, IEEE 2nd International Conference on Photonics (ICP). (2011) 1-4.

[5] J. Petroski, Spacing of high-brightness LEDs on metal substrate PCB's for proper thermal performance, The Ninth Intersociety Conference on Thermal and Thermomechanical Phenomena in Electronic Systems, Proc. ITHERM'04. Las Vegas USA. (2004) 507-514.

[6] N. Narendran, Life of LED-based white light sources, Display Technology, Journal of Display Technology. 11 (2005) 167-171. 